\title{
Qualification of laser based additive production for manufacturing of forging Tools
}

\author{
Daniel Junker ${ }^{1, \mathrm{a}}$, Oliver Hentschel ${ }^{2}$, Michael Schmidt $^{2}$, and Marion Merklein ${ }^{1}$ \\ ${ }^{1}$ Insitute of Manufacturing Technology, Egerlandstr. 13, 91058 Erlangen, Germany \\ ${ }^{2}$ Insitute of Photonic Technologies, Konrad-Zuse-Str. 3-5, 91052 Erlangen, Germany
}

\begin{abstract}
Mass customization leads to very short product life cycles, so the costs of a tool have to be amortized with a low number of workpieces. Especially for highly loaded tools, like those for forging, that leads to expensive products. Therefore more economical production processes for tool manufacturing have to be investigated. As laser additive manufacturing is already used for the production of moulds for injection moulding, this technology maybe could also improve the forging tool production. Within this paper laser metal deposition, which is industrially used for tool repair, will be investigated for the use in tool manufacturing. Therefore a mechanical characterization of parts built with different laser process parameters out of the hot work tool steel 1.2709 is made by upsetting tests and hardness measurements. So the influence of the additive manufacturing process on the hardness distribution is analysed.
\end{abstract}

\section{Introduction}

As the customers desire on individual products increases, the companies offer a large portfolio of customized products. As the so called mass customization requires a high number of different parts also many different tools are needed for the production of those parts. As the individualization of parts is not just limited to design elements but also desired for functional highly loaded parts, this trend expends towards the forging industry. Forging tools, above all cold forging tool are cost intensive, so individual products that have to be produced by forging will be excessively expensive. To realize the mass customization, a more economical way in manufacturing forging tools has to be investigated.

Additive manufacturing offers the possibility of a highly flexible production at acceptable costs for a low number of pieces. As it is already used for the production of moulds for injection moulding, the usability for the production of forging tools will be investigated here. Forging tools are highly loaded with mechanical stresses, thermal stresses and wear and therefore request a higher hardness and higher strength than moulds [1]. Especially the laser based processes laser deposition melting and laser beam melting, which will be explained in the following part, are two technologies that can expand the processes used in tool manufacturing.

\footnotetext{
${ }^{\text {a }}$ Corresponding author: daniel.junker@fau.de
}

This is an Open Access article distributed under the terms of the Creative Commons Attribution License 4.0, which permits unrestricted use, distribution, and reproduction in any medium, provided the original work is properly cited. 
a)

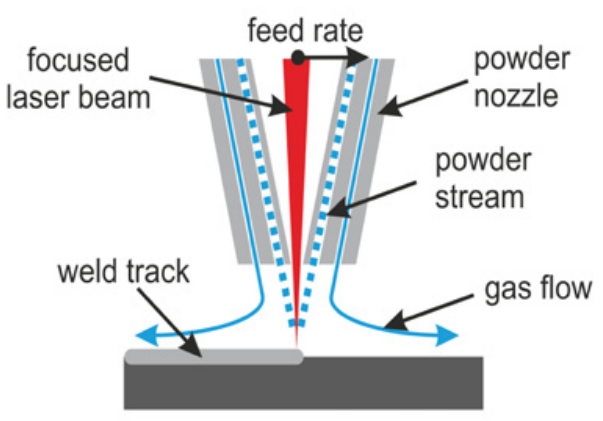

b)

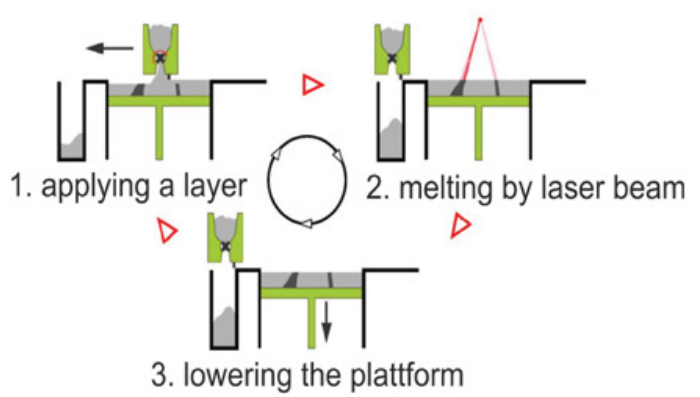

Figure 1. Illustration of the principle of (a) laser metal deposition (LMD) and (b) laser beam melting (LBM) [5].

\section{Laser based additive manufacturing processes}

The principle of laser metal deposition (LMD) is schematically illustrated in Fig. 1(a). Thereby the surface of a metallic part is selectively fused by a focused laser beam. Simultaneously metallic powder is injected in the generated melting pool by a powder nozzle. For three-dimensional applications such as coating of tools, repair of turbine blades or additive manufacturing of parts, coaxial powder-nozzles are used. This prevents fluctuations of the particle distribution in the powder stream, resulting in bad welding track quality, respectively deviations from ideal welding track geometry. After cooling down and solidification of the molten substrate and powder material a welding track is formed on the substrate surface. By the steady progression of the laser metal deposition equipment it is nowadays even possible to generate three-dimensional structures on freeform surfaces. In this context single welding tracks are closely placed next to each other and on top of each to build up the requested part geometry layerwise [2]. The thickness of the dilution zone between substrate and deposited welding tracks is usually significantly smaller than the welding track height. Assuming ideal process conditions the dilution ratio should be in the order between $10 \%$ and $20 \%$ of the clad height [3].

In comparison the laser beam melting (LBM) uses a powder bed, which allows the production of more complicated geometries, since the powder prevents collapsing of hollow parts. Furthermore it is possible to build support structures that can be removed after producing the parts. Commonly the whole part is built on such support structures to reuse the building platform. The schematic illustration exposed in Fig. 1(b) shows the principle of LBM. First a layer of powder of $20 \mu \mathrm{m}$ or $50 \mu \mathrm{m}$ is placed on the building platform by a recoater. Afterwards the powder is melted partially by a laser scanner. Before repeating these two steps the building platform is lowered by the height of one layer [4].

In the field of tool making the LMD process is nowadays used for the repair and maintenance of worn forging tools. Tools are locally repaired by adding new material at worn out sections and are milled for a smooth surface afterwards. Another industrially established application of LMD in the tool making industry is the deposition of wear protection coatings. In this context ceramic particles such as $\mathrm{WC}$ or TiC are embedded in a tool steel matrix in order to improve the wear resistance by increasing the hardness. Within the scope of the BMBF supported project "Multifunktionale Gradientenwerkstoffe für den Werkzeugbau" the generation of wear protection coatings based on metal-matrix-composite layers are investigated for different tool steel matrix materials [6].

The industrial usage of laser beam melting in terms of tool manufacturing is the production of moulds for injection moulding. Because of the geometrical freedom in fabrication, tempering channels can be placed near to the surface for a more homogeneous and also faster cooling than it is possible with conventional moulds [7]. There are also some investigations on building forging tools by LBM by using 
Table 1. Experimental design for the varied Parameter at the LMD process laser power in W and hatch distance in $\%$ of a single welding bead.

\begin{tabular}{|l|c|c|c|c|c|c|c|c|c|}
\hline & A & B & C & D & E & F & G & H & I \\
\hline Hatch & $80 \%$ & $100 \%$ & $120 \%$ & $80 \%$ & $100 \%$ & $120 \%$ & $80 \%$ & $100 \%$ & $120 \%$ \\
\hline Laser Power & \multicolumn{3}{|c|}{$600 \mathrm{~W}$} & \multicolumn{3}{c|}{$700 \mathrm{~W}$} & \multicolumn{3}{c|}{$800 \mathrm{~W}$} \\
\hline
\end{tabular}

of low carbon tool steel like 1.2709, since materials with a higher amount of carbon cannot be processed within the LBM [8].

As the main aim of the project presented in this paper, is the production of cold forging tools by additive manufacturing, tool materials with a high strength and a high hardness have to be used, which includes materials with an amount of carbon up to 1.5 per cent, which are difficult to weld. Since LMD is already used to repair forging tools [9] and it enables the usage of multiple different materials within the process, this technology is chosen for further investigations on the production of forging tools. Within this paper the influence of the additive manufacturing principle and the used process parameters on mechanical properties of the parts will be analysed.

\section{Experimental setup}

To qualify parts build by the LMD process, upsetting tests and hardness measurements are made with specimens built with various process parameters. In the following the experimental setup will be explained. As 1.2709 is a common used tool steel in additive manufacturing, this hot work tool steel is used for the initial testing. It is a precipitation hardening steel that has to be artificial aged at a pretty low temperature of $490^{\circ} \mathrm{C}$ for 6 hours and has to be cooled slowly on air to harden up to $560 \mathrm{HV}$. To lower the hardness down to $320 \mathrm{HV}$, solution annealing at a temperature of $900{ }^{\circ} \mathrm{C}$ for 1 hour with quenching in water can be executed.

\subsection{Laser metal deposition}

The experiments are conducted at the Institute of Photonic Technologies with the laser metal deposition machine TLC 3008 from the company Trumpf GmbH. As laser source a disk laser with a wavelength of $1030 \mathrm{~nm}$ and a maximum averaged laser power of $1 \mathrm{~kW}$ is used. The spot diameter in the working plane (on the substrate) is kept constant to $1.5 \mathrm{~mm}$. Extended series of experiments are conducted in order to define a process window to build up defect-free and dense cubic test structures made of 1.2709. The tool steel powder showed an approximately spherical particle shape and possessed a particle size between $20 \mu \mathrm{m}$ und $63 \mu \mathrm{m}$. The cubic test structures with an edge length of $15 \mathrm{~mm}$ are directly welded on common 1.2343 tool steel substrates. The experimental design for building the cubic structures for the compression specimens is shown in Table 1 . The powder mass flow is set to $5.7 \mathrm{~g} / \mathrm{min}$ and the feed rate to $400 \mathrm{~mm} / \mathrm{min}$.

\subsection{Upsetting test}

To analyse the strength of the additive manufactured parts, cylinders with a diameter and a height of $10 \mathrm{~mm}$ are milled out of the cubes. To investigate the mechanical properties of the workpiece after hardening specimens of the parameter variation A and D are artificial aged for 6 hours at 490 degrees Celsius. Additionally specimens of 1.2709 are turned out of a wire with $30 \mathrm{~mm}$ diameter, to compare the mechanical properties of conventional and additive manufactured tool steel 1.2709.

The upsetting tests are made at the Institute of Manufacturing Technology on a universal testing machine Walter\&Bai from Zwick//Roell with a maximum force of $300 \mathrm{kN}$. Because of the high load during compression testing a carbide tool is used. For constant low friction conditions a teflon film is 


\section{MATEC Web of Conferences}

Table 2. Results of YS and $\mathrm{FS}_{(0.3)}$ of upsetting tests of additively built specimens by different process parameters and of conventional tool steel 1.2709.

\begin{tabular}{|c|c|c|c|c|c|c|c|c|c|c|}
\hline & A & B & $\mathrm{C}$ & $\mathrm{D}$ & $\mathrm{E}$ & $\mathrm{F}$ & G & $\mathrm{H}$ & I & Conv. \\
\hline Hatch [\%] & 80 & 100 & 120 & 8 & 100 & 120 & 80 & 100 & 120 & \\
\hline Laser Power & \multicolumn{3}{|c|}{$600 \mathrm{~W}$} & \multicolumn{3}{|c|}{$700 \mathrm{~W}$} & \multicolumn{3}{|c|}{$800 \mathrm{~W}$} & \\
\hline $\begin{array}{l}\mathrm{YS}\left[\mathrm{N} / \mathrm{mm}^{2}\right] \\
\text { (SD) }\end{array}$ & $\begin{array}{l}977 \\
( \pm 7)\end{array}$ & $\begin{array}{l}967 \\
( \pm 17)\end{array}$ & $\begin{array}{l}1014 \\
( \pm 15)\end{array}$ & $\begin{array}{l}965 \\
( \pm 6)\end{array}$ & $\begin{array}{l}954 \\
( \pm 11)\end{array}$ & $\begin{array}{l}970 \\
( \pm 7)\end{array}$ & $\begin{array}{l}951 \\
( \pm 6)\end{array}$ & $\begin{array}{l}972 \\
( \pm 20)\end{array}$ & $\begin{array}{l}953 \\
( \pm 6)\end{array}$ & $\begin{array}{l}953 \\
( \pm 3)\end{array}$ \\
\hline $\begin{array}{l}\mathrm{FS}_{(0.3)}\left[\mathrm{N} / \mathrm{mm}^{2}\right] \\
(\mathrm{SD})\end{array}$ & $\begin{array}{l}1383 \\
( \pm 3)\end{array}$ & $\begin{array}{l}1406 \\
( \pm 63)\end{array}$ & $\begin{array}{l}1460 \\
( \pm 18)\end{array}$ & $\begin{array}{l}1314 \\
( \pm 53)\end{array}$ & $\begin{array}{l}1333 \\
( \pm 17)\end{array}$ & $\begin{array}{l}1388 \\
( \pm 29)\end{array}$ & $\begin{array}{l}1393 \\
( \pm 24)\end{array}$ & $\begin{array}{l}1381 \\
( \pm 23)\end{array}$ & $\begin{array}{l}1373 \\
( \pm 14)\end{array}$ & $\begin{array}{l}1184 \\
( \pm 1)\end{array}$ \\
\hline
\end{tabular}

put in between the specimen and the tool. The tests are executed with a compression velocity of $5 \mathrm{~mm} / \mathrm{s}$ and the specimen is compressed to $50 \%$ of the initial height or until the force limit of the machine of $290 \mathrm{kN}$ is reached. To analyse the upsetting tests by means of a flow curve the experiments are observed with an optical strain measurement system named ARAMIS from GOM mbH. That system measures the real strain during the tests and allows, in combination with the used force, the calculation of a real flow curve.

\subsection{Hardness measurement}

As an inhomogeneous forming behaviour of the specimens could be observed, the micro hardness of some samples is measured. Therefore untested specimens are measured to analyse the influence of the process parameters form the LMD process on the hardness within each layer. The measurements are made on the Fischerscope HM2000 from the Helmut-Fischer GmbH that allows a high resolution measurement of the Vickers Hardness (HV0.5). The cubes are measured with a constant distance of $0.4 \mathrm{~mm}$ between the measurement points and as they just show a variation of the hardness in $\mathrm{z}$-direction of the additive built, the specimens are measured with a vertical distance of $0.2 \mathrm{~mm}$ and a horizontal distance of $1 \mathrm{~mm}$.

\section{Results and discussion}

The results of the upsetting tests are shown in the Table 2. The analysis is made on the yield stress (YS) and the flow stress at a forming degree of $0.3\left(\mathrm{FS}_{(0.3)}\right)$.

First the influence of the laser power for the different hatch distances on the YS will be analysed. The specimens build with a hatch distance of $100 \%$ show the highest standard deviation and therefore no significant influence of the laser power can be identified. For a hatch distance of $80 \%$, YS increases with lower laser power. At a hatch distance of $120 \%$ that effect enhances significantly. Analysing the same parameters on the flow stress at 0.3 degree of deformation, no significant influence of the laser power is seen for $80 \%$ and $100 \%$ hatch distance. For a hatch distance of $120 \%$ the specimens built with a laser power of $600 \mathrm{~W}$ shows significantly the highest YS. So it can be summarized that for lower laser power a wider hatch distance leads to a higher stress.

Comparing all specimens built additively with the bulk material the YS is in the same range but slightly higher. At 0.3 degrees of deformation an increasing of approximately $200 \mathrm{~N} / \mathrm{mm}^{2}$ of the flow stress can be recognized. Furthermore the standard deviation of $\mathrm{FS}_{(0.3)}$ increases compared to that of YS, so forming behaviour of the parts varies in a large range, which could be caused by structural differences induced by the laser. As shown in Fig. 2, an inhomogeneous forming behaviour of the specimens could be observed during the upsetting tests. Since no inhomogeneous inner structure could be identified by a microscopic analysis, a micro hardness measurement is made. The results are shown in Fig. 2.

A hardness variation in vertical direction can be identified. The hardness measurement also explains the shape of the specimen after forming. As there is a correlation between hardness and yield strength, 


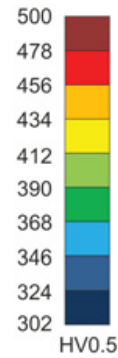

a)
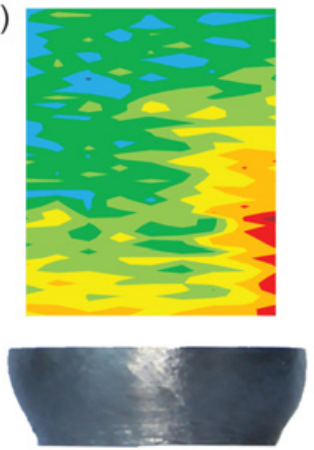

b)

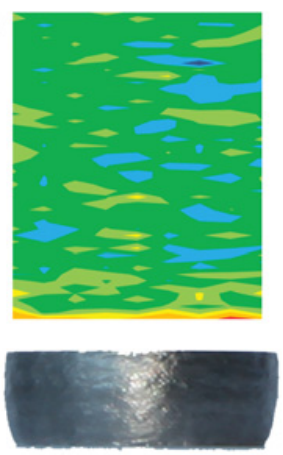

Material 1.2709

$\dot{V}_{\text {Powder }}=5.7 \mathrm{~g} / \mathrm{min}$

$\mathrm{v}=400 \mathrm{~mm} / \mathrm{min}$

a) $\mathrm{P}=700 \mathrm{~W}$

$\mathrm{d}_{\text {Hatch }}=80 \%$

b) $\mathrm{P}=800 \mathrm{~W}$

$\mathrm{d}_{\text {Hatch }}=80 \%$

Figure 2. Micro hardness of untested and geometry of the tested samples of (a) set D (700W; $80 \%)$ and (b) set G (800W; 80\%).

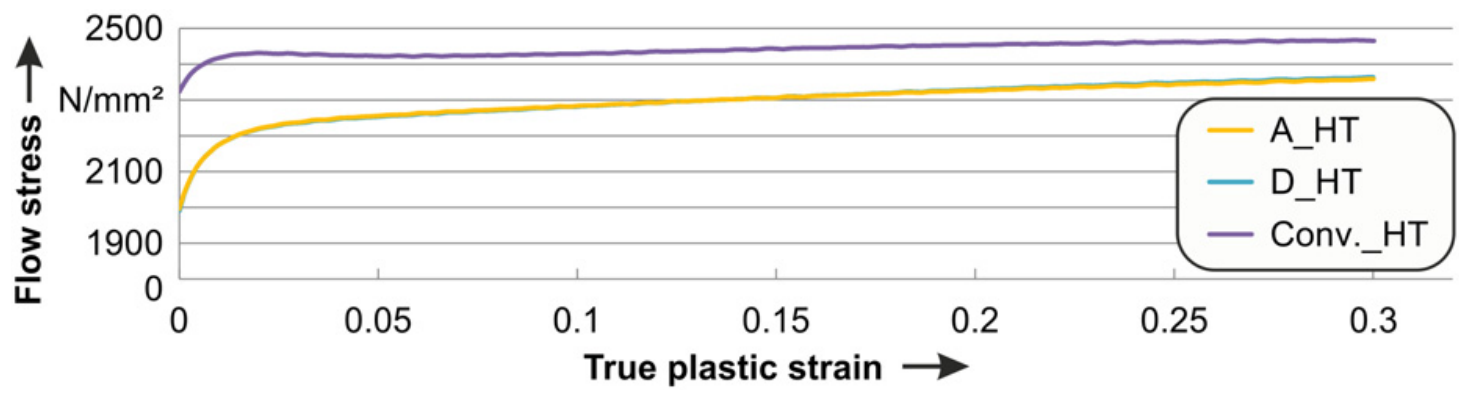

Figure 3. Exemplary flow curves of heat treated (HT) specimens of set A (600W, 80\%), set D (700W, 80\%) and conventional steel 1.2709 after heat treatment.

areas with lower hardness are easier to deform, which causes the irregular shape of the tested specimen shown in Fig. 2. It also can be seen, that the structure built with higher laser power show a more homogeneous hardness distribution as well as a more ideal shape after testing. An explanation could be the materials behavior at different temperatures.

As explained before, 1.2709 is hardened by low temperatures with a slow cooling and weakened by high temperatures and quenching. During the additive manufacturing the surface is molten, where new material is added. That results in a high temperature and by heat conduction the heat flows into the part. As the additive process a continuous welding of tracks next to each other and layer on layer, heat is brought into the part continuously. Since the heat conduction cannot transfer all the induced heat, it leads to a temperature gradient with high temperature near the melting temperature at the actual working point that lowers down at higher distance from that point.

The heat induced is depended on the energy input, which results from scan speed focus diameter and laser power. As scan speed and focus diameter were constant within these experiments only the laser power affected the heating. Therefore higher laser power causes a higher energy input that heat up the part. For a high energy input the whole part is held at higher temperatures, what is similar to solution annealing and therefore causes a decreasing of the hardness. By a lower energy input the layers far from the working surface are not affected that much by the induced heat and are held by a lower temperature similar to the artificial ageing. Therefore the hardness gradient is higher in parts built with lower laser power. 


\section{MATEC Web of Conferences}

As tool steel is commonly used in a hardened state an investigation of the mechanical characteristics after heat treatment is made for set A $(600 \mathrm{~W} ; 80 \%)$ and D $(700 \mathrm{~W} ; 80 \%)$ to identify an influence of the laser power. After the artificial ageing, a homogenization occurred and the inhomogeneous forming behavior was eliminated. The results of the tests are shown in Fig. 3.

After heat treatment the YS of additively build specimens is lower than that of conventional 1.2709. But the additive manufactured parts show a higher work hardening exponent and approach to the strength of conventional steel at a degree of deformation of 0.3. The measured YS is similar to that found in the literature for parts built by LBM that were identified by tensile tests [10]. As the principle of additive manufacturing is a build-up welding, the reduced strength after hardening can be explained by the structural behaviour of that steel after welding. During the welding an austenitic structure is formed within the heat affected zone. This region does not change the structure during the artificial ageing [11]. Since at additive manufacturing many of these heat affected zones are put to each other, the total strength of the additive manufactured part after hardening is reduced. Nevertheless a surface hardness of about $530 \mathrm{HV}$ can be measured that fulfils the requirements of a hot forging tool, so the process can be used for producing these tools.

\section{Summary and outlook}

To qualify the laser metal deposition for tool manufacturing the influence of additive manufacturing on mechanical properties is analysed by upsetting tests and hardness measurements. Therefore specimens built with different process parameters are produced and tested. It could be identified that for this hot work tool steel 1.2709 for lower laser power used within the LMD process a wider hatch distance leads to a higher strength. At a higher laser power that phenomenon did not occur. Furthermore a hardness gradient in building direction could be detected that depends on the used laser power. So a high energy input leads to a more homogeneous inner structure and therefore to an ideal forming behaviour. As tool steels are used in a hardened condition additive built and conventional specimens are compared after artificial ageing. For the additive manufactured parts built with variant parameters, no difference could be identified but the mechanical properties of the tested specimens are lower than those of conventional steel. At least a surface hardness of about $530 \mathrm{HV}$ was measured for the additive manufactured specimens, which fulfils the requirement of hot forging tools.

Further investigation will deal with more common tool steel 1.2343, which has a higher percentage of carbon therefore is not easy to process by laser additive manufacturing. Instead of a decrease of hardness on the surface, as it could be identified for 1.2709, an increasing of the hardness of 1.2343 is expected for the heat treatment induced by the laser.

The work presented in the paper was kindly founded by the Bavarian research foundation (BFS) in the course of the Research Association "ForNextGen - Next Generation Tools". The authors would also like to thank the Bavarian State Ministry for Science, Research and Art in the course of the programme Nuremberg Campus of Technology (NCT) that supported a part of this work.

\section{References}

[1] K. Lange, M. Liewald, Umformtechnik, Band 2 (1988)

[2] E. Toyserkani, A. Khajepour, S. Corbin, CRC Press (2004)

[3] G.J. Bruck, G. Sepold Ed., 14-28 (1988)

[4] W. Meiners, Dissertation RWTH Aachen (1999)

[5] E. Yasa, K. Kempen, J.-P. Kruth, Proceedings of the 21st Anual International Solid Freeform Fabrication (SFF) (2010) 
[6] A. Weisheit, E. Fuchs, BMBF Nr. 03N5045 (2006)

[7] S. Jansen, Dissertation RWTH Aachen (2014)

[8] A. Husic, B.-A. Behrens, J. Giedenbacher, A. Husic, Schmiede JOURNAL 09/13 (2013)

[9] K. Eimann, M. Drach, Tagungsband Aachner Kolloquium Lasertechnik AKL 2000 (2000)

[10] Material data sheet 1.2709, LaserBearbeitungCenter GmbH

[11] G. Madhusudhan Reddy, V.V. Rao, A.V.S. Raju, Proceedings of the Institution of Mechanical Engineers, Part L, 149-159 (2009) 